University of Nebraska - Lincoln

DigitalCommons@University of Nebraska - Lincoln

June 2000

\title{
From the Psychiatric Hospital to the Community: Integrating Conditional Release and Contingency Management
}

\author{
Eric B. Elbogen \\ University of Nebraska - Lincoln, elbogen@unlserve.unl.edu
}

Alan Tomkins

University of Nebraska, atomkins@nebraska.edu

Follow this and additional works at: https://digitalcommons.unl.edu/publicpolicytomkins

Part of the Public Policy Commons

Elbogen, Eric B. and Tomkins, Alan, "From the Psychiatric Hospital to the Community: Integrating Conditional Release and Contingency Management" (2000). Alan Tomkins Publications. 14.

https://digitalcommons.unl.edu/publicpolicytomkins/14

This Article is brought to you for free and open access by the Public Policy Center, University of Nebraska at DigitalCommons@University of Nebraska - Lincoln. It has been accepted for inclusion in Alan Tomkins Publications by an authorized administrator of DigitalCommons@University of Nebraska - Lincoln. 


\title{
From the Psychiatric Hospital to the Community: Integrating Conditional Release and Contingency Management
}

\author{
Eric B. Elbogen, M.A., and Alan J. Tomkins, J.D., Ph.D.
}

Psychiatric hospital recidivism has been and continues to be a persistent problem in treating individuals with chronic mental illness. Conditional release, a form of involuntary outpatient commitment, has been suggested as one possible solution. Guided by therapeutic jurisprudence, this article presents a proposal about conditional release that would maximize convergence of social values and would be empirically testable. Specifically, a scientifically validated treatment intervention for individuals with chronic mental illness, contingency management, is integrated with conditional release. From this proposal, a number of empirical hypotheses and legal questions about discharging psychiatric patients are generated and discussed.

\footnotetext{
$\mathrm{D}^{\mathrm{s}}$ ischarging patients from the psychiatric hospital to the community is almost always a challenging task for clinicians. Mental health professionals must contend with the fact that a significant percentage of patients discharged will be readmitted to inpatient psychiatric facilities shortly after being discharged to the community. Releasing individuals with chronic mental illness (CMI), who have a history of numerous hospitalizations, is particularly difficult. Empirical findings regarding recidivism rates vary, but, in general, research indicates that approximately one-fourth to one-half of individuals with CMI demonstrate signs of relapse that warrant rehospitalization within six months of being released to the community (e.g., Casper, 1995; Lidz, Mulvey, \& Gardner, 1993; Schoenbaum, Cookson, \& Stelovich, 1995). This phenomenon, often called "the revolving door

* Correspondence to: Eric B. Elbogen, M.A., or Alan J. Tomkins, J.D., Ph.D., UNL Law/Psychology Program, 238 Burnett Hall, Lincoln, NE 68588-0308, USA. Email addresses: elbogen@unlserve.unl.edu or atomkins2@unl.edu. Eric Elbogen is an advanced graduate student in the UNL Law/Psychology Program. Alan Tomkins is Director of the University of Nebraska Public Policy Center and Professor, Law/Psychology Program. The authors would like to thank Robert Schopp and David Wexler for their helpful suggestions and assistance. This article is based on a paper, "Contingency Management Beyond Discharge Through Monitored Conditional Release: Violence Risk Assessment and Treatment of Individuals with Chronic Mental Illness," presented at the First International Conference on Therapeutic Jurisprudence, Winchester, July 1998. Professor Bruce Winick served as Action Editor for this article.
} 
cycle," occurs when "individuals regress to another crisis, only to end up back in the hospital" (McCafferty \& Dooley, 1990, p. 278). There is some indication that revolving door patients in the United States have proliferated significantly in the past decade for a variety of reasons ranging from deinstitutionalization to managed care (see generally Hiday, 1996). Psychiatric hospital recidivism has been and continues to be a persistent problem in treating individuals with CMI.

One proposed solution to the revolving door cycle involves the use of involuntary outpatient commitment (IOC) in the context of discharge. Sometimes used as an alternative to initial civil commitment, IOC may also be connected with discharge plans (McCafferty \& Dooley, 1990). Two forms of IOC that have been recommended as options for discharge are "conditional release," in which patients are discharged subject to certain behavioral requirements, and "outpatient commitment," in which discharged patients must meet regularly with a treatment provider in the community (Hinds, 1990). Discharge from psychiatric hospitals involves a change in legal status that invariably leaves some individuals with CMI vulnerable to the increased stress of independent living (Brakel, Parry, \& Weiner, 1985). The use of either conditional release or outpatient commitment could, ideally, make the transition from the hospital to the community both safe and therapeutic. If this were the case, then it is reasoned IOC could reduce relapse for individuals with CMI and break the revolving door cycle (Hiday, 1996).

Does continuity of care provided by IOC between inpatient and outpatient settings decrease the chances of rehospitalization? This question is especially pertinent to ask from the perspective of therapeutic jurisprudence (see generally Sales, 1995; Symposium, 1992, 1993; Wexler, 1991a; Wexler \& Winick, 1991, 1996; Winick, 1997). The guiding orientation of TJ is to examine "the extent to which substantive rules, legal procedures, and the roles of lawyers and judges produce therapeutic or antitherapeutic consequences" (Wexler \& Winick, 1991, p. ix). Therapeutic jurisprudence is concerned with examining how the law is utilized in ways that either promote or frustrate mental health. Using a therapeutic jurisprudence lens, therefore, would seem relevant for investigations into the therapeutic impact of IOC on patients with CMI.

An analysis of mental health issues under the umbrella of therapeutic jurisprudence will address several important goals (see generally Schopp, 1995; Wexler \& Winick, 1996). First, the therapeutic jurisprudence framework encourages analysis of an individual's interactions with the law to identify instances or contexts in which mental health interventions might be beneficial for the individual. This analysis has been characterized as looking for "psycholegal soft-spots" (Wexler, 1992, 1998). Psycholegal soft spots afford the opportunity to apply the law as a "therapeutic agent" (Wexler, 1995, p. 230). From this perspective, the therapeutic and anti-therapeutic consequences of mental health law, practice, or policy are explicitly considered.

Second, the therapeutic jurisprudence framework explicitly encourages analysis of whether seemingly conflicting values that emerge in legal contexts can be addressed simultaneously. The challenge is to maintain adhesion to diverse values, to the extent possible, rather then completely eschew important mental health or legal goals at the expense of others. For example, as Schopp (1995) writes, "Rather than debating the priorities among individual well-being, self-determination, and public safety, therapeutic jurispru- 
dence scholarship seeks novel ways to avoid conflicts among these values by promoting legal developments that maximize convergence between them" (p. 164). Whereas traditional mental health law often reflects policy determinations that choose between individual well-being, self-determination, or public safety (Glendon, 1991; Keilitz, 1992), therapeutic jurisprudence asks us to reframe how we understand the questions and challenges us to create mental health policies that enhance individual well-being, self-determination, and public safety, simultaneously.

Third, therapeutic jurisprudence encourages the empirical examination of laws, policies, and practices that are generated or implemented (Wexler, 1991a, p. 17). Therapeutic jurisprudence is concerned less with issues of general theory but rather emphasizes the need for empirically testable hypotheses that permit validation of the therapeutic impact of mental health laws, policies, and practices (Schopp, 1995; Slobogin, 1995). Scientific confirmation or refutation of therapeutic-jurisprudence-inspired hypotheses is ultimately necessary. Therapeutic jurisprudence, unlike other legal perspectives, is explicitly concerned with translating legal scholarship into "real world" clinical gains (see Elbogen \& Tomkins, in press; Finkelman \& Grisso, 1994; see also Wexler \& Schopp, 1992; Wexler \& Winick, 1991, pp. xi, 8).

Using the therapeutic jurisprudence framework, some scholars have initiated a psycholegal soft-spot examination of IOC in the context of discharge. Heilbrun (1997) maintains that enlisting a patient's participation at the time of discharge could help patients set self-imposed risk reduction goals they understand and feel are within their control. The use of either conditional release or outpatient commitment is hypothesized to complement such efforts and help clinicians monitor patients in order to reduce violent behavior in the community. Wexler (1991b) argues that principles of health care compliance derived from cognitive therapy suggest that greater patient involvement in discharge planning could facilitate therapeutic goals. Wexler proposes that conditional release would provide a venue for forensic patients to more actively engage in their treatment plans (see also Wexler, 1996). Through the lens of therapeutic jurisprudence, IOC used at discharge from psychiatric hospitals has been identified as a psycholegal soft spot with the potential to reduce the revolving door cycle among individuals with CMI.

Conditional release and the revolving door cycle have yet to be explored with respect to the other goals of therapeutic jurisprudence. In order to advance the therapeutic jurisprudence research agenda, the purpose of this article is to generate a proposal about conditional release that would maximize convergence of values and that would be empirically testable. First, we evaluate the potential of IOC and other discharge alternatives to promote different social values. According to therapeutic jurisprudence, the most preferable discharge plan for individuals with CMI is one that maximizes convergence between selfdetermination, individual well-being, and public safety. To meet this end, efforts are made to incorporate risk assessment technology and effective rehabilitative treatment, specifically contingency management, into discharge planning through the use of conditional release. Consequently, an empirically testable proposal is presented to integrate conditional release and contingency management in discharge planning from psychiatric hospitals. The proposal is examined, and various implications for reducing the revolving door cycle and relapse in the community for individuals with CMI are discussed. 


\section{EVALUATING INVOLUNTARY OUTPATIENT COMMITMENT AT DISCHARGE}

There theoretically could be a continuum of options that are used to structure the different types of discharge from an inpatient facility. On one end of the continuum, the patient may be granted an unconditional release, typically called an "absolute discharge." This is the most common form of release from inpatient civil commitment and involves a complete termination of the legal relationship between the institution and the patient (Brakel et al., 1985). Jurisdictions vary in how absolute discharge is administered. Models of absolute discharge include the following types: (a) administrative, in which responsibility is placed in the hands of the psychiatric facility; (b) judicial, in which responsibility is placed in the hands of the courts; or (c) hybrids of the previous two, such as in Idaho, Oregon, and Wisconsin, where the authority of discharge has been vested in the hands of a central agency (Brakel, 1988). Despite these differences, each version of absolute discharge involves release from the hospital with no conditions and does not ensure followup services in the community.

At the other end of the continuum, patients may be released into the community subject to certain conditions, such as IOC. Such discharges include legally required community follow-up after discharge and maintenance of a legal relationship between the patient and the psychiatric hospital. With "IOC discharges," individuals with CMI would be legally mandated to attend treatment on an outpatient basis once released (McCafferty \& Dooley, 1990). As mentioned above, two types of IOC, conditional release and outpatient commit-

ment, can be used at discharge to permit a transition to the community from the institution (Hinds, 1990). Since the mid-1980s, the vast majority of states (40) have provided for conditional release or outpatient commitment (Brakel et al., 1985). Nonetheless, IOC has rarely been employed as a discharge alternative (Hiday, 1996; Van Horn, 1994).

It should be noted that there might be instances in which patients voluntarily choose to have certain conditions for discharge. Even though they may be conditional, such releases would not be considered IOC discharges. For example, a patient may request an outpatient commitment and thereby not receive an IOC. Or, a patient may wish to live in a structured residential facility as a condition of his or her discharge. To the extent that IOC can be framed to permit patient choice, it may contribute to long term treatment compliance and reduce rehospitalization (Wexler, 1991b). In such cases, patients would be released under what could be called "voluntary outpatient commitment." Although further discussion of this type of discharge goes beyond the scope of this article, it is important to recognize that such releases do fall on the aforementioned continuum.

Given the potential influence of the law in the context of discharge from psychiatric facilities, therapeutic jurisprudence would recommend that discharge be analyzed to identify the presence of any psycholegal soft spots. To examine IOC as a psycholegal soft spot, it is important to ask "How do absolute versus IOC discharges compare with respect to their potential for promoting important social values?" Public safety best seems promoted using IOC discharges because they permit monitoring of risk of relapse or violence in the community (Hiday, 1996). Recent advances in risk assessment technology have improved the ability to predict violent behavior (Borum, 1996), and risk assessments can be on-go- 
ing with IOC discharges rather than one, final assessment as is used in absolute discharges. IOC also affords continuity of care between hospital and community and permits more effective responses by mental health providers to patient changes which precipitate relapse (Hinds, 1990). Overall, IOC discharge better ensures public safety because absolute discharge lacks continued monitoring of risk of violence.

On the other hand, it is less obvious which type of discharge better promotes self-determination. Prima facie, because absolute discharge has no strings attached, this alternative would seem to more likely increase patient autonomy. While this is true, in one sense, it also can be argued that IOC increases, rather than decreases, a patient's overall autonomy and liberty interests. IOC is a mechanism aimed at encouraging "hospital staff [to] release an individual into the community once his/ her condition has improved to the point that inpatient care is no longer necessary" (McCafferty \& Dooley, 1990, p. 277). In other words, hospital staff might be more likely to release a patient with an IOC rather than to absolute discharge because of the continued monitoring afforded by the former. In this sense, IOC might actually facilitate discharge and has the chance to grant individuals more autonomy than absolute discharge (see Mulvey, Geller, \& Roth, 1987). Furthermore, if IOC could be used as a forum to increase patient involvement in treatment, then it would contribute to the development of patient autonomy (Heilbrun, 1997; Wexler, 1991b). More careful philosophical inquiry is required to assess which discharge option better promotes self-determination (see also Schopp, 1995).

Therapeutic jurisprudence also prompts us to consider the potential therapeutic benefits to individual well-being of discharge alternatives. IOC discharge appears to have certain advantages over absolute discharge in this respect because of the continued legal relationship between treatment provider and patient. Transitioning patients slowly permits better adjustment to the community from inpatient hospital life (Bachrach, 1978). The legal intervention of IOC, therefore, can be used toward helping individuals with CMI cope and adapt to independent living (Brakel et al., 1985). Further, the presence of psychiatric disorder may limit a patient's ability to use aftercare services (see Miller \& Fiddleman, 1984). For example, individuals with CMI may be unable to use public transportation or may not understand the benefits of counseling and psychotherapy. IOC discharges could, at least, help assure that patients are discharged with needed resources available in the community.

Some empirical studies have documented how IOC combats the revolving door cycle. Hiday and Scheid-Cook (1991) specifically targeted patients with a high risk to be rehospitalized and found that patients who were ordered by courts to outpatient treatment were more likely to attend their community mental health center than those who were not. Research has shown consistently that the use of outpatient services after discharge is associated with improved functioning and fewer admissions (see Hinds, 1990). Another empirical study concluded that individuals who received an outpatient commitment showed fewer rehospitalizations compared to patients who were discharged without an outpatient commitment (Munetz, Grande, Kleist, \& Peterson, 1995). Widerlanders (1992) also found that conditional release contributed to a decrease of recidivism and violent behavior in forensic patients (see also McGreevy, Steadman, Dvoskin, \& Dollard, 1991). Other efforts to employ IOC at discharge have shown success, as well (for a review, see Hiday, 1996). 
Overall, IOC discharges appear to show more potential than absolute discharges for promoting individual well-being and public safety. Further, to extend that IOC reduces length of hospital stays and incorporates opportunities to promote autonomy, however, IOC discharges also support self-determination.

Despite its potential benefits, however, IOC discharges pose a number of serious problems that absolute discharges avoid. First, as with civil commitment, substantial legal issues for IOC need to be addressed (see generally Hinds, 1990). Specifically, it is unclear what the legal criteria for IOC should be. For example, what if a patient with an outpatient commitment stopped attending therapy but was living appropriately in the community? What if a patient were to break one of the conditions of his release, but was able to manage his disorder and did not break the other conditions of his release? Questions therefore arise about when the IOC conditions have not been met and revocation and recommitment should be sought. Consequently, IOC statutes might implicate issues of due process. In many states, for instance, conditional release is often revoked without formal court hearings, thus suggesting possible violation of patients' due process (Van Horn, 1994). Additionally, laws protecting inpatients' right to refuse medication have not, as yet, been applied in the context of IOC; thus, it has been maintained that the patient's right to refuse medications might be stronger for inpatient commitment than IOC (McCafferty \& Dooley, 1990; Schmidt \& Geller, 1989). A number of constitutional issues thus surround the use of IOC at discharge.

Second, mental health professionals have voiced clinical concerns with IOC. Some clinicians do not believe that any form of involuntary treatment can be effective and thus disagree with IOC on ideological grounds (see Mulvey et al., 1987). Additionally, outpatient clinicians have reported that they are reluctant to carry caseloads of high-risk clients (McCafferty \& Dooley, 1990). Some clinicians have claimed that added legal paperwork makes IOC an unattractive treatment option (Reed \& Lewis, 1990). A recent national survey found that IOC was only considered "common" or "very common" in 12 states (Torey \& Kaplan, 1995). It appears that mental health professionals tend to use IOC as a discharge option only sparingly (e.g., Van Horn, 1994). Finally, it is important to note that empirical research has not yet established that IOC works consistently to reduce the revolving door cycle (Maloy, 1996). There are as many studies that indicate no therapeutic benefits from employing IOC as there are studies that indicate some benefit.

Third, implementation of IOC programs engenders a number of practical problems, as well. The cost of providing IOC has been cited as one chief reason why IOC has not been used more frequently (Torey \& Kaplan, 1995). In many jurisdictions, there are not enough resources (e.g., residential placements) to treat inpatients who would otherwise be conditionally released (McCafferty \& Dooley, 1990). Enforcement of IOC has also been problematic, as well (Hiday, 1996). Initiating rehospitalization of an IOC client requires mental health professionals to consult with attorneys and devote relatively more attention to the case. Because commitment hearings consume a great deal of time (which also might cause delays in treatment) clinicians may be deterred from consistently enforcing the conditions of IOC programs, thereby rendering IOC programs less effective. For these reasons, IOC might be a less-than-viable discharge option.

Fourth, IOC poses several ethical dilemmas that should be considered. Ethical problems with discharge in general have been noted in the literature, specifically regarding the 
proper roles and responsibilities of the inpatient provider (see Schopp, 1996). Schopp argues inpatient mental health professionals have an ethical dilemma deciding whether to absolutely discharge a patient: they must act as both treatment provider and law enforcement agent. Absolute discharges make explicit which agency possesses the legal authority to release patients. However, IOC arguably makes the roles and responsibilities involved in discharge more confusing because IOC also requires participation of courts and outpatient providers in the decision making process. Currently, courts have handled this division of responsibility in IOC schemes in a myriad of ways, placing authority to discharge in the hands of the psychiatric facility, a mental health board, the court, or outpatient clinicians (Hinds, 1990). At present, it seems unclear who bears ultimate responsibility for the discharge decision when it comes to IOC.

\section{EXTENDING CONTINGENCY MANAGEMENT BEYOND DISCHARGE}

IOC represents a potentially serviceable discharge strategy for reducing the revolving door cycle, but do the problems outweigh the benefits? If IOC were to be used at discharge, therapeutic jurisprudence would recommend that a program of IOC be developed that maximizes convergence between different values (Schopp, 1995). From this perspective, discharge plans that promote public safety, self-determination, and individual wellbeing are preferable. Thus, if a modest proposal can be generated that both enhances the convergence of these values and addresses each of the problems of IOC mentioned above, then IOC can be made a viable and effective discharge plan.

Efforts to incorporate risk assessment technology into an IOC program would help address public safety needs (see generally Heilbrun, 1997; Monahan \& Steadman, 1994). Wexler's $(1991 b, 1994)$ proposal that conditional release be used as a forum to promote patient involvement in discharge planning would encourage self-determination. A major stumbling block appears to be that mental health professionals themselves are divided on the potential therapeutic benefits of IOC. One reason for this may be that no specific protocols for IOC programs have been proposed; indeed, recommendations for IOC have not been based on scientifically validated treatment. In particular, therapeutic jurisprudence would point out that if a proposal were to best promote individual well-being, then it should be based on treatment modalities that have been demonstrated empirically (Wexler \& Winick, 1996; Winick, 1997). To date, specific guidelines for IOC derived from the scientific literature on therapeutic interventions have not been proposed. This may, in part, explain the lack of consistency in treatment efficacy of IOC (see generally Hiday, 1996; Maloy, 1996). A proposal that incorporates state-of-the-art treatment for individuals with CMI into an IOC scheme thus seems warranted.

An IOC proposal guided by therapeutic jurisprudence would attempt to maximize mental health benefits. In a recent review of interventions aimed at increasing treatment compliance and reducing violent behavior, Harris and Rice (1997) conclude that very few effective techniques exist. The authors note, however, that the use of contingency management is an exception to this rule:

The most convincing evidence supporting behavioral methodology for addressing the problems of psychiatric patients (including aggression) is that of Paul and Lentz, who showed that specialized contingency 
management reduced aggression among chronic psychotic patients and gave them the skills necessary to leave the hospital and live in the community ... (p. 1172).

The contingency management system of Paul and Lentz (1979), also called a "token economy system," has been used in the United States to treat and rehabilitate individuals with CMI on acute, forensic, and chronic psychiatric units (Corrigan \& Liberman, 1994). There are two key elements to the token economy system. First, target behaviors must be established. These include both behaviors to be avoided (e.g., aggressive outbursts, delusional speech) and behaviors to be encouraged (e.g., medication compliance, proper hygiene/ grooming). Second, there must be delivery of consistent consequences for the occurrence of each target. Often, units use a "level" system by which a patient earns or loses "privileges" and works his/her way toward discharge by showing cooperative and pro-social behaviors and by avoiding aggressive, deviant, or self-destructive behaviors. Thus, individuals with CMI "learn" to not show symptomatic behaviors. Empirical studies have demonstrated consistently the efficacy of this type of behavioral modification in treating individuals with CMI (Liberman, 1991; Liberman \& Bedell, 1989).

On an inpatient milieu, an individual with CMI can obtain the skills necessary to function appropriately and to live safely in society through the use of contingency management systems. However, one major criticism of contingency management is that it does not always generalize from the hospital setting into the community (Corrigan, 1995). Together with the need to retrain staff to deliver this type of intervention, contingency management has not gained as much widespread acceptance as it probably should (see Corrigan \& Liberman, 1994). However, token economies have been shown to be more cost effective than the traditional custodial milieu (Harris \& Rice, 1997). Additionally, they have been demonstrated to reduce noncompliance for all types of behavior in different psychiatric settings (e.g., Beck, Menditto, \& Baldwin, 1991: reducing aggressive behavior in a forensic setting; Etschiedt, 1991: increasing self-control for behaviorally disordered adolescents; Shloss, Smith, \& Santora, 1989: reducing anger responses in dually diagnosed individuals with mental retardation).

Still, the issue of generalizability into the community remains because token economy systems are typically maintained as inpatient treatment only. This is an especially critical point for contingency management because the cornerstone of this treatment is consistency in delivering consequences for target behaviors. If the target behaviors cannot be consistently reinforced, in the community after discharge, then the efficacy of treatment is dramatically reduced. If, however, this contingency management can be extended into the community after discharge, then it should continue to be effective.

Conditional release may provide a partial solution to this problem. Conditional release has been recommended for insanity acquittees after discharge (see generally Bloom \& Williams, 1994). Conditional release also is available for civil committees, and Van Horn (1994) argues for its application to reduce the revolving door cycle. Court-sanctioned discharge plans of monitoring certain behaviors in the community and of readmitting patients to the hospital if they fail to follow their plan should provide continuity of mental health services into the community. For example, a patient may be required upon discharge to take his medication, abstain from drug use, and see an outpatient therapist to monitor his 
paranoid and disorganized thoughts. Essentially, the patient is monitored in the community for the very same behaviors that he would be monitored for on the inpatient setting.

In a sense, conditional release is used to transfer some of the inpatient treatment into an outpatient setting. If this is the case, might conditional release, appropriately used, afford an opportunity to extend contingency management beyond discharge? Could the law be used as a therapeutic agent? In other words, might not the inpatient target behaviors form the outpatient conditions of release? Target behaviors, to the degree that behavioral observations can be made, can be identical to those in the hospital. Conditional release would also permit the delivery of consequences for each target just like an inpatient contingency management plan. The legal consequence of being rehospitalized can be seen as "losing a level" just as on the inpatient unit. Such consequences ideally could be delivered consistently, as well. And, finally, the contingency management can be conducted in a non-hospital and naturalistic milieu: the community. This way, both IOC and empirically validated psychosocial rehabilitation can be joined into a comprehensive discharge plan for individuals with CMI.

\section{INTEGRATING CONDITIONAL RELEASE AND CONTINGENCY MANAGEMENT}

Below, we present a proposed set of clinical procedures aimed at integrating conditional release and contingency management. Formal risk assessment, interventions to increase patient participation, and elements of contingency management are combined in a way that seeks to increase public safety, self-determination, and individual well-being, respectively. Each step of the clinical procedures includes several empirically testable hypotheses. As such, the proposal is shaped and guided by the therapeutic jurisprudence research program, although the therapeutic jurisprudence orientation makes evaluation neither easier nor more difficult (see generally Wolff, 1998, 1999).

\section{Step 1-Discharge Risk Assessment}

The goal of integrating conditional release and contingency management is to incorporate target behaviors from inpatient treatment into the outpatient setting. Target behaviors in the conditional release would include those used on the inpatient setting as well as information generated from following three types of risk assessment. First, recent advances in risk assessment technology would be exploited. In particular, actuarial instruments that statistically combine empirically validated risk factors would be used because they have been shown to greatly increase the accuracy of risk predictions (Borum, 1996). For example, the HCR-20 is an assessment tool designed to provide structured guidelines for assessing dangerousness in forensic and psychiatric populations (Webster, Eaves, Douglas, \& Winthrup, 1995). The MacArthur Violence Risk Assessment Study is also in the process of developing a decision-tree designed to assist clinicians assess risk of violent behavior in acute psychiatric settings (see Steadman et al., 1998). Other instruments, such as 
the Violence Risk Appraisal Guide (VRAG), have already been shown to provide actuarial measures of dangerousness in certain populations (Harris \& Rice, 1997).

The second approach to risk assessment would be to determine unique risk factors and idiosyncratic patterns of relapse that are not captured by formal risk assessment instruments (Melton, Petrila, Poythress, \& Slobogin, 1997). Conducting idiographically oriented risk assessments in this manner has been called the "anamnestic" approach (Miller \& Morris, 1988). Anamnestic risk assessment supplements the actuarial based findings because the latter involves a fixed set of variables, which may not all apply in particular cases. Further, anamnestic assessments allow for clinicians to hone in on the specific circumstances that lead to relapse. For example, a patient might have a peculiar pattern of becoming increasingly anxious and paranoid after visiting a certain relative, which has, in the past, led to his becoming delusional, noncompliant with medications, and, subsequently, psychotic and dangerious. Anamnestic, but not actuarial, approaches to risk assessment would consider this type of important information.

The third element of the discharge risk assessment would include some form of patient input. As others have hypothesized, the more patient involvement in treatment can be facilitated, the more likely the patient will be compliant (see Wexler, 1991b) and nonviolent (see Heilbrun, 1997). Additionally, patient input can indicate the extent to which the patient understands and agrees to comply with his discharge plan (Elbogen \& Tomkins, in press). Models to promote patient involvement in discharge planning are not new (e.g., Nightingale, 1990), and cognitive-behavioral therapy has advocated this approach to counteract noncompliance for over a decade (see Miechenbaum \& Turk, 1987). Though empirical work has not yet confirmed this specific cognitive-behavioral theroy, patients' perceptions about the quality of the treatment they are receiving does appear to be related to positive outcome and treatment compliance (see generally Tyler, 1992; Wexler \& Winick, 1996).

A comprehensive discharge risk assessment would ideally involve these three elements. An objective risk assessment test would point to the patient's general level of risk and to dynamic risk factors that are significant predictors of relapse. The anamnestic approach would identify individual patterns of behavior that typically lead to relapse. Patient input on his/her own risk factors would be essential to determine which factors/patterns of relapse generated from the first two approaches he/she agrees with or understands. Similar to risk assessment research currently being conducted (Monhan \& Steadman, 1994), empirical studies would test whether each or all three approaches increase accuracy of clinical judgements or reduce chances of relapse or violent behavior in the community. Combined with the target behaviors from the contingency management, these risk factors would be used to inform the patient's conditions of release.

\section{Step 2-Court-Ordered Conditional Release}

The inpatient clinician and patient together would draft the petition for conditional release. Behavioral scientist have recently suggested that patients perceive less coercion when they are afforded a "voice" in the civil commitment process (Greer, O'Regan, \& Traverso, 1996; Tyler, 1992). Communication between clinical staff and hospitalized pa- 
tients that encourages resolving disputes in a fair manner may therefore impact on patient autonomy and treatment involvement (Susman, 1996). Toward this end, Wexler (1994) recommends that behavioral contracts be used to promote therapeutic goals. He states, 'One who makes a 'public' commitment to comply-a commitment to persons above and beyond the medical provider-is more likely to comply than one who does not make such a public commitment" (p. 260). From this perspective, conditional release can be seen as a chance to forge a behavioral contract involving the court, patient, hospital, outpatient providers, and family members. If patients agree and sign on to the conditions of release, it is therefore hypothesized to generate greater compliance after discharge (Winick, 1997). Although there may be highly treatment-resistant patients who refuse to comply with any treatment plan, there are at least some patients in psychiatric hospitals who do have enough insight into their disorder to know they need outpatient treatment. Providing a venue for such patients could reinforce realistic judgment making and give them credit for their role in their treatment decisions.

A court report would be written in which the patient's target behaviors and risk factors inform the conditions for discharge. The court could refuse to grant a conditional release and still voice concerns about the patient's safety or ability to function independently. Or, the court could grant the conditional release request, perhaps adding some conditions of its own. Either way, the court would make the ultimate legal decision on the patient's discharge and make the release contingent on certain conditions. The court would also specify the amount of time the period of conditional release would last. Currently, this conditional release period varies by jurisdiction, but usually lasts a few months (see Hinds, 1990; Van Horn, 1994). Empirical investigation would be needed to determine the most effective time frame for the conditional release period.

\section{Step 3-Patient Discharge}

The court would then communicate its decision to the inpatient facility (and the patient's attorney). If conditional release were granted, inpatient clinicians could place the patient on discharge status and prepare for release. This preparation, in part, would include the important step of obtaining a release of information from the patient and sending to each of the patient's outpatient providers (including psychiatrist, counselor, case manager, residential manager) copies of the discharge risk assessment and the court-ordered conditional release. This way, all mental health professionals that would come into contact with the patient would be aware of exactly the same behaviors to monitor; thus, some degree of consistency of the contingency management program can be achieved.

Additionally, the patient would be given a copy of both reports to facilitate greater involvement in his/her discharge plan. Further, if the patient reads that the target behaviors are in fact listed in the court document, then the consequences for breaking the conditions of release are made even clearer to the patient, which, again, is another essential element of contingency management. Empirical examination of a patient's perceptions about his treatment plan could be conducted to determine whether reading the court document enhances motivation to comply with the conditional release. Once the inpatient unit has en- 
sured that outpatient providers and the patient all agree to, and understand, the provisions of the discharge plan, the patient would be ready to be discharged assuming other logistical problems have been solved.

\section{Step 4-Conditional Release Period}

During this period of conditional release, the patient should be monitored for the same set of target behaviors by each of the patient's treatment providers. This may be accomplished in various ways, depending on the target behavior. Urine toxic screens can be used if a patient must stay sober and clean as a condition of release. Medication levels can be checked with blood tests, when appropriate, to ensure medication compliance. If the patient has a case manager, weekly or biweekly meetings could be arranged in order to gauge how well the patient is adjusting to the community, especially at the beginning of the patient's transition to the community. Although behaviors cannot be monitored as closely in the community as on inpatient units, there are ways to monitor behavior in the community that could be effective.

What happens if a patient does not meet all the conditions of release? As noted above, different jurisdictions handle this problem in a variety of ways, from requiring a court hearing to rehospitalizing a patient as soon as the conditional release is broken. This administrative issue will likely be a challenge to this scheme; however, if the patient breaks the conditional release and is blatantly psychotic, homicidal, aggressive, or suicidal, then a separate commitment hearing seems less indicated, and revocation of the conditional release appears appropriate. If the patient breaks the conditional release on one occasion (e.g., does not show for therapy) but does not appear to have decompensated, it is less clear whether revocation is warranted until the reason for the noncompliance is discovered. For example, King (1995) found that noncompliance with IOC sometimes results from lack of transportation or for other logistical, and otherwise, extra-clinical reasons. If the patient breaks the conditional release for other, less innocuous reasons, though, then the court is in the proper role and responsibility to make the revocation decision (see generally Schopp, 1996). Thus, a due process hearing should be held in such cases to determine whether revocation of conditional release is called for.

\section{Step 5-Follow-up Risk Assessment}

If the conditional release is not broken and the patient is compliant with aftercare plans, the patient would be seen at the predetermined time for a follow-up evaluation of his/her risk of relapse. Most conditional release statutes currently do not incorporate any type of contact between the patient and mental health professionals or legal authorities at the end of the conditional release period. However, empirical research indicates that such followup may be critical to reducing recidivism. In a recent study of 580 discharged psychiatric patients, Schoenbaum et al. (1995) found that readmission was less likely for subjects who made a follow-up visit to a mental health facility within 30 days of discharge. Simi- 
larly, Thomas, Ernst, and Ernst (1992) determined that inpatients who made contact with the inpatient clinic within three months after discharge had greater levels of compliance with aftercare plans than those who did not make this contact. Finally, Austad and Shapiro (1986) interviewed inpatient clinicians and determined that postdischarge contact had a positive impact on patient's treatment and therapy in the community. A follow-up visit would seem to be indicated from the scientific literature.

The date for such a discharge contact would fall toward the end of the conditional release period so that the follow-up risk evaluation could be sent to the court to be considered in its decision making. Before discharge, the exact time and date should be negotiated with and agreed to by the patient, as research has shown that verbal agreement on a postdischarge appointment itself leads to greater compliance (Thomas et al., 1992). It is hypothesized that there will be greater compliance with the conditional release if the patient sets his or her own date for the post-discharge follow-up. This date would need to be communicated to outpatient providers so that they could supply updates on the patient's progress in the community, specifically with regard to the conditions of release/target behaviors of discharge plan. This way, multiple sources of data would be generated by treatment providers for the post discharge risk evaluation.

If the patient had been hospitalized for a long period of time (greater than six months), it would seem appropriate to set the follow-up risk assessment at the inpatient facility, particularly because staff there would know the patient best. However, for shorter hospitalizations, it may make just as much sense to have outpatient providers conduct the follow-up. Empirical studies need to establish which option is better for which patients. In either scenario, treatment providers' reports would ideally be sent to the evaluating clinician sometime before the evaluation. The clinician would then meet with the patient, ask about relapse/risk factors, conduct a mental status examination, make behavioral observations, and inquire about the patient's experiences in the community. After the risk assessment, the clinician would summarize all reports and assessment data with regard to the extent to which the patient has complied with the conditions of release. Before the end of the conditional release period, the clinician would send this evaluation to the court and make recommendations based on the clinical evidence.

\section{Step 6-Follow-up Court Decision on Conditional Release}

At the end of the conditional release period, the court would decide whether to revoke, continue, or terminate the patient's conditional release status based, in part, on the followup risk assessment. The court would report its decision to the clinician who conducted the follow-up risk assessment, who would in turn communicate this information to treatment providers and the patient. If the conditional release were revoked, then a civil commitment hearing would need to take place to ensure due process (Van Horn, 1994). If the conditional release were continued, steps 4 and 5 would be repeated. If the conditional release were terminated, patients would need to be told that noncompliance with target behaviors could precipitate a civil commitment hearing or involuntary hospitalization if they 
decompensate and become dangerous to themselves or others. No matter which decision is reached, outpatient clinicians should capitalize on the force of the law in order to reinforce the consequences for engaging, or not engaging, in target behaviors. This way, contingency management can continue to some degree even after the conditional release period has ended.

\section{ASSESSING CONTINGENCY MANAGEMENT- CONDITIONAL RELEASE}

This proposal is expected to yield several clinical benefits. First, the scheme should permit better transfer to the community of skills learned in contingency management inpatient programs. Second, our proposed system of a follow-up evaluation should generate a feeling of accomplishment for individuals with CMI derived from having lived independently in the community. Third, incorporating patient input into the conditional release via the initial risk assessment should enhance patient involvement in treatment planning. Fourth, conditional release would make the patient realize that he or she could be rehospitalized; knowledge of this contingency should create an incentive for the patient to be treatment compliant. Despite these benefits, it must be acknowledged that clinicians may still be resistant to use the program because of the added paperwork and logistical difficulties involved. Determining ways to lessen the burden for already overworked mental health professionals will be key to implementation of this proposal.

In addition to addressing some of the clinical concerns with IOC, the scheme addresses some of the legal problems mentioned above. Although many conditional release programs currently do not include commitment hearings before revocation, we argue that hearings should be held before revocation because they would appropriately protect patients' due process. By clarifying the conditions of release in the list of target behaviors and risk factors, revocation procedures can be made less ambiguous to outpatient providers. Surveys found that clinicians were reluctant to use IOC because of fears they would become embroiled in complicated legal situations (McCafferty \& Dooley, 1990). Under this proposal, if the conditional release is violated, treatment providers can refer to the conditional release plan in a relatively straightforward manner to indicate the target behaviors or risk factors under question.

Fiscal issues remain, however, because available community placement is limited (see Torey \& Kaplan, 1995). This scheme would generate additional costs, including increased phone contact between agencies and additional work hours devoted to report writing. Courts would have to spend additional resources reviewing these reports and overseeing commitment hearings for conditional release revocation. However, these costs arguably would be less than inpatient hospital costs. Compared with the expense of inpatient hospitalization stays, such financial costs do not seem overbearing, particularly if reduction in recidivism can be demonstrated. One estimate calculates that IOC could eliminate 15-30 days of inpatient hospitalization per patient per year and thereby reduce health care costs for that patient by an average of $\$ 16,000$ annually (Kress, 1999). This IOC program should be an economically viable discharge alternative and save money in the long run if it were run appropriately. 
Finally, this scheme may reduce ethical problems. By providing contact between inpatient and outpatient providers, the roles of clinicians in discharging a patient are more clearly delineated. Further, by including the courts in the discharge decision, the question regarding whether the patient should be released to the community is answered by the courts. Questions of balancing public safety versus personal liberty should be the role and responsibility of courts, not clinicians (see generally Schopp, 1996). Finally, the patient's own involvement in the discharge planning appropriately assigns the patient's responsibility in following through with the conditions of release. The roles and responsibilities of all four entities involved (inpatient unit, outpatient providers, courts, and patient) can therefore be better clarified in this proposal.

From this analysis, then, it is apparent that this proposal generates a number of empirical and legal questions that need to be examined before implementation. Empirically, it will be especially important to operationalize outcome measures of treatment efficacy. Might there be alternatives to "recidivism" that would be equally important to quantify, including patient level of functioning, perceptions of coercion, and satisfaction with the discharge plan? Additionally, how much time between discharge and follow-up would be optimally therapeutic-one month, two months, six months, or one year? Also, should this follow-up occur in the original inpatient context? Perhaps it would enhance outcomes to have the risk evaluation conducted in outpatient clinical settings? Finally, the empirical question remains: Does incorporating risk factors into a conditional release plan aimed at extending contingency management in the community actually reduce hospital recidivism? Some studies have shown that IOC in some cases may in fact increase recidivism in the short run because patients are more closely monitored than before (see Hinds, 1990). What impact will implementation of this proposal have?

Legal questions arise from this proposal, as well. It is still left unclear what courts should do in cases where conditions of release are not met but no patient decompensation occurs (for a discussion of this issue, see, Van Horn, 1994). A major concern of outpatient clinicians in employing IOC is the fear of liability if high-risk clients commit violent acts. How then would this proposal influence liability for negligent release if a patient commits a violent act during the CR period? Do the roles and responsibilities of all the parties involved in this proposal need to be made more specific? Additionally, the problem of forced medication in the community exists in the proposed conditional release plan. The right to refuse medication in IOC is left unclear and, until this legal issue is better clarified, will likely remain problematic with implementation of the proposal (see generally Mulvey et al., 1987). The proposal also raises questions regarding the class of individuals for whom this scheme should apply. Civil commitment due to violence raises different legal issues than civil commitment due to suicidal gestures (see, e.g., Monahan \& Steadman, 1994). Risk assessment follow-up into the community would seem especially appropriate for a group of difficult-to-manage high risk clients (Heilbrun, 1997; Steadman et al., 1994). However, the exact criteria for choosing which patients would be appropriate for this IOC scheme still needs to be worked out. 


\section{CONCLUSION}

The idea of conjoining the law to effective psychosocial treatment is encouraged by therapeutic jurisprudence. Clearly, using the law as a tool for purposes of promoting effective psychosocial interventions is not unique to therapeutic jurisprudence (see, e.g., Melton, 1986; Melton et al., 1997; Wolff, 1998). Nonetheless, therapeutic jurisprudence is a useful research orientation that promotes (a) the identification of psycholegal soft spots that potentially enhance therapeutic benefits, (b) the generation of proposals and practices to maximize convergence of what otherwise are seen as competing values in the mental health law system, and (c) the empirical assessment of the therapeutic impact of intervention proposals and practices. This article has sought to include IOC at discharge as a possible contribution to the therapeutic jurisprudence agenda. Our suggestion applies conditional release to the discharge of individuals with CMI in a way that promotes different social values and permits empirical testing, while at the same time addresses deficits currently cited in both the IOC and contingency management literature. With respect to IOC, a more effective therapeutic model for delivery is offered, which should appeal to clinicians and thereby bolster its use. With respect to contingency management, a means by which to extend token economy systems into the community is presented.

In the end, the kinds of problems posed by this proposal will require further inquiry no matter what particular program of IOC is adopted. With deinstitutionalization emptying state hospitals and with homeless and jail populations consisting of growing numbers of individuals with CMI, the revolving door cycle is ever increasing. As a result, IOC is seen as a viable and important alternative for following patients into the community after discharge. Therapeutic jurisprudence helps frame an IOC discharge plan designed to promote important social values and to be empirically testable. Given the division among mental health professionals about IOC, a therapeutically sound and convincing IOC proposal may be the best means by which IOC can generate the support of those who treat individuals with CMI and, ultimately, be incorporated into regular clinical practice.

\section{REFERENCES}

Austad CS, Shapiro RS. 1986. Treatment implications of postdischarge contact. Hospital and Community Psychiatry 37: 839-840.

Bachrach LL. 1978. A conceptual approach to deinstitutionalization. Hospital and Community Psychiatry 29: 573578.

Beck NC, Menditto AA, Baldwin L. 1991. Reduced frequency of aggressive behavior in forensic patients in a social learning program. Hospital and Community Psychiatry 42: 750-752.

Bloom JD, Williams MH. 1994. Management and Treatment of Insanity Acquitees: A Model for the 1990s. American Psychiatric Press: Washington DC.

Borum R. 1996. Improving the clinical practice of violence risk assessment. American Psychologist 51: 945-956.

Brakel SJ. 1988. Legal schizophrenia and the mental health lawyer: Recent trends in civil commitment litigation. Behavioral Sciences and the Law 6: 3-14.

Brakel SJ, Parry J, Weiner BA. 1985. The Mentally Disabled and the Law. American Bar Foundation: Chicago, IL.

Casper ES. 1995. Identifying multiple recidivists in a state hospital population. Psychiatric Services 46: 1074-1075.

Corrigan PW. 1995. Use of token economy with seriously mentally ill patients: Criticisms and misconceptions. Psychiatric Services 46: 1258-1263.

Corrigan PW, Liberman RP. 1994. Behavior Therapy in Psychiatric Hospitals. Springer: New York.

Elbogen EB, Tomkins AJ. The psychiatric hospital and therapeutic jurisprudence: Applying the law to promote mental health. New Directions in Mental Health Services in press.

Etschiedt S. 1991. Reducing aggressive behavior and improving self-control: a cognitive-behavioral training program for behaviorally disordered adolescent. Behavior Disorders 16: 107-115. 
Finkelman D, Grisso T. 1994. Therapeutic Jurisprudence: From idea to application. New England Journal on Criminal and Civil Confinement 20: 243-257.

Glendon MA. 1991. Rights Talk: The Impoverishment of Political Discourse. Free Press: New York.

Greer A, O'Regan M, Traverso A. 1996. Therapeutic jurisprudence and patient's perceptions of procedural due process of civil commitment hearings. Law in a Therapeutic Key: Developments in Therapeutic Jurisprudence, Wexler D, Winick B (eds). Carolina Academic Press: Durham, NC; 923-934.

Harris GT, Rice ME. 1997. Risk appraisal and management of violent behavior. Psychiatric Services 48: 11681176.

Heilbrun K. 1997. Prediction versus management models relevant to risk assessment: The importance of legal decision-making context. Law and Human Behavior 21: 347-359.

Hiday VA. 1996. Outpatient commitment: Official coercion in the community. Coercion and Aggressive Community Treatment: A New Frontier in Mental Health Law, Dennis DL, Monahan J (eds). Plenum: New York.

Hiday VA, Scheid-Cook TL. 1991. Outpatient commitment for "revolving door" patients: Compliance and treatment. Journal of Nervous and Mental Disease 179: 83-88.

Hinds JT. 1990. IOC for the chronically mentally ill. Nebraska Law Review 69: 346-412.

Keilitz I. 1992. Justice and mental health systems interactions: An overview and introduction to the special issue. Law and Human Behavior 16: 1-4.

King EF. 1995. Outpatient civil commitment in North Carolina: Constitutional and policy concerns. Law and Contemporary Problems 58: 251-281.

Kress K. 1999, April. Should Iowa adopt an outpatient treatment statute? Paper presented at the meeting of the National Alliance for the Mentally Ill, Johnson County, IA.

Liberman RP. 1991. Handbook of Psychiatric Rehabilitation. Pergamon: Elmsford, NY.

Liberman RP, Bedell JR. 1989. Behavior therapy. Comprehensive Textbook of Psychiatry, 5th ed, Kaplan H, Sadock B (eds). Williams and Wilkins: Baltimore, MD.

Lidz C, Mulvey E, Gardner W. 1993. The accuracy of predictions of violence to others. Journal of the American Medical Association 269: 1007-101 1.

Maloy K. 1996. Does involuntary outpatient commitment work? Mental Health and Law: Research, Policy, and Services, Sales BD, Shah S (eds). Carolina Academic Press: Durham, NC; 41-70.

McCafferty GA, Dooley J. 1990. Involuntary outpatient commitment: An update. Mental and Physical Disability Law Reporter 14: 277-283.

McGreevy MA, Steadman HJ, Dvoskin JA, Dollard N. 1991. New York State's system of managing insanity acquitees in the community. Hospital and Community Psychiatry 42: 512-517.

Melton GB (ed.). 1986. The Law as a Behavioral Instrument. University of Nebraska Press: Lincoln, NE.

Melton G, Petrila J, Poythress N, Slobogin C. 1997. Psychological Evaluations for the Courts: A Handbook for Mental Health Professionals and Lawyers, 2nd ed. Guilford: New York.

Miechenbaum D, Turk D. 1987. Facilitating Treatment Adherence: A Practitioner's Guidebook. Miller M, Morris N. 1988. Predictions of dangerousness: An argument for limited use. Victims and Violence 3: 262-272.

Miller RD, Fiddleman PB. 1984. Outpatient commitment: Treatment in the least restrictive alternative environment? Hospital and Community Psychiatry 35: 147-151.

Monahan J, Steadman H (eds). 1994. Violence and Mental Disorder: Developments in Risk Assessment. University of Chicago Press: Chicago, IL.

Mulvey EP, Geller JL, Roth LH. 1987. The promise and peril of involuntary outpatient commitment. American Psychologist 42: 571-584.

Munetz MR, Grande T, Kleist J, Peterson GA. 1995. The effectiveness of outpatient civil commitment. Psychiatric Services 47: 1251-1253.

Nightingale J. 1990. Discharge planning: Promoting patient involvement through group process. Social Work with Groups 13: 83-94.

Paul GL, Lentz RJ. 1979. Psychosocial Treatment of Chronic Mental Patients: Milieu versus Social-Learning Programs. Harvard University Press: Cambridge, MA.

Reed S, Lewis D. 1990. The negotiation of voluntary admission in Chicago's state mental hospitals. Journal of Psychiatry and Law 18: 137-163.

Sales BD (ed.). 1995. Therapeutic jurisprudence [special theme]. Psychology, Public Policy, and Law 1(1).

Schmidt MJ, Geller JL. 1989. Involuntary administration of medication in the community: The judicial opportunity. Bulletin of the American Academy of Psychiatry and the Law 17: 283-292.

Schoenbaum SC, Cookson D, Stelovich S. 1995. Postdischarge follow-up of psychiatric inpatients and readmission in an HMO setting. Psychiatric Services 46: 943-945.

Schopp RF. 1995. Sexual predators and the structure of the mental health system: Expanding the normative focus of therapeutic jurisprudence. Psychology, Public Policy, and Law 1: 161-192.

Schopp RF. 1996. Communicating risk assessments: Accuracy, efficacy, and responsibility. American Psychologist 51: 939-944. 
Shloss PJ, Smith M, Santora C. 1989. A respondent conditioning approach to reducing anger responses of a dually diagnosed man with mild mental retardation. Behavior Therapy 20: 459-464.

Slobogin C. 1995. Therapeutic jurisprudence: Five dilemmas to ponder. Psychology, Public Policy, and Law 1: 193219.

Steadman H, Monahan J, Appelbaum P, Grisso T, Mulvey E, Roth L, Robbins P, Kalssen D. 1994. Designing a new generation of risk assessment research. Violence and Mental Disorder Developments in Risk Assessment, Monahan J, Steadman H (eds). University of Chicago Press: Chicago, IL; 297-318.

Steadman H, Mulvey E, Monahan J, Clark-Robbins P, Appelbaum P, Grisso T, Roth L, Silver E. 1998. Violence by people discharged from acute psychiatric inpatient facilities and by others in the same neighborhoods. Archives of General Psychiatry 55: 393-402.

Susman J. 1996. Resolving hospital conflicts: A study on therapeutic jurisprudence. Law in a Therapeutic Key: Developments in Therapeutic Jurisprudence, Wexler D, Winick B (eds). Carolina Academic Press: Durham, NC; 907-922.

Symposium. 1992. Psychological jurisprudence: Another perspective. Southern Methodist University Law Review 46: $323-445$.

Symposium. 1993. Therapeutic jurisprudence: Restructuring mental disability law. New York Law School Journal of Human Rights 10: 623-914.

Thomas H, Ernst C, Ernst K. 1992. How to obtain compliance for aftercare following psychiatric hospitalization. Nervenarzt 63: 442-443.

Torey EF, Kaplan RJ. 1995. A national survey of the use of outpatient commitment. Psychiatric Services 46: 778784.

Tyler TR. 1992. The psychological consequences of judicial proceedings: Implications for civil commitment hearings. Southern Methodist University Law Review 46: 433-445.

Van Horn PE. 1994. Revocation of CR in New York state: What process is due? Columbia Journal of Law and Social Problems 27: 523-556.

Webster C, Eaves D, Douglas K, Winthrup A. 1995. The HCR-20 Scheme: The Assessment of Dangerousness and Risk. Simon Fraser University and Forensic Psychiatric Services Commission of British Columbia: Burnaby.

Wexler DB. 199la. An introduction to therapeutic jurisprudence. Essays in Therapeutic Jurisprudence, Wexler DB, Winick BJ (eds). Carolina Academic Press: Durham, NC; 17-38.

Wexler DB. 1991b. Health care compliance principles and the insanity acquittee CR process. Criminal Law Bulletin 27: $18-41$.

Wexler DB. 1992. Putting mental health into mental health law: Therapeutic jurisprudence. Law and Human Behavior 16: 27-38.

Wexler DB. 1994. An orientation to therapeutic jurisprudence. New England Journal on Criminal and Civil Confinement 20: 254-264.

Wexler DB. 1995. Reflections on the scope of therapeutic jurisprudence. Psychology, Public Policy, and Law 1: 230-236.

Wexler DB. 1996. Some therapeutic jurisprudence implications of the outpatient civil commitment of pregnant substance abusers. Law in a Therapeutic Key: Developments in Therapeutic Jurisprudence, Wexler D, Winick B (eds). Carolina Academic Press: Durham, NC; 145-148.

Wexler DB. 1998. Practicing therapeutic jurisprudence: Psycholegal soft spots and strategies. Revista Juridica Universidad de Puerto Rico 67: 317-342.

Wexler DB, Schopp RJ. 1992. Therapeutic jurisprudence: A new approach to mental health law. Handbook of Psychology and Law, Kagehiro DK, Laufer WS (eds). Springer: New York; 361-381.

Wexler DB, Winick B J (eds). 1991. Essays in Therapeutic Jurisprudence. Carolina Academic Press: Durham, NC. Wexler DB, Winick BJ (eds). 1996. Law in a Therapeutic Key: Developments in TJ. Carolina Academic Press: Durham, NC.

Widerlanders MR. 1992. Recidivism of disordered offenders who were conditionally vs. unconditionally released. Behavioral Sciences and the Law 10: 141-148.

Winick BJ. 1997. Coercion and mental health treatment. Denver University Law Review 74: 1145-1168.

Wolff N. 1998. Interactions between mental health and law enforcement systems: Problems and prospects for cooperation. Journal of Health Politics, Policy, and Law 23: 133-174.

Wolff N. 1999, November. Research as a policy tool: A mismatch between randomized controlled trials and the real world of services research. Paper presented at the meeting of the Association for Public Policy Analysis and Management, Washington, DC (November). 